\title{
ON THE REDISTRIBUTIVE PROPERTIES OF PRESUMPTIVE TAXATION
}

\author{
ALESSANDRO BALESTRINO \\ UMBERTO GALMARINI
}

CESIFO WORKING PAPER No. 1381

CATEgory 1: Public FinANCE

JANUARY 2005
An electronic version of the paper may be downloaded
- from the SSRN website:
www.SSRN.com
- from the CESifo website:
www. CESifo.de




\title{
ON THE REDISTRIBUTIVE PROPERTIES OF PRESUMPTIVE TAXATION
}

\begin{abstract}
Presumptive taxation, in which an income proxy is used as tax base, has been and is still used today in countries with very diverse situations - developing, transition and developed countries. Usually, this form of taxation is thought of as a revenue-raising device in presence of widespread imperfect tax compliance. We investigate the question of whether presumptive taxation can be used as a redistributive instrument. To this end, we employ an occupational choice model in which an individual can be either an entrepreneur or a worker. We allow for different abilities to dodge taxes across social classes, and consider both the case in which a conventional income tax is in place alongside presumptive taxation and the case in which only presumptive taxation is operating. We argue that a revenue-neutral reform introducing a lump-sum presumptive tax based on occupational choice can improve social welfare, and sometimes even lead to a Pareto-improvement.
\end{abstract}

JEL Code: H21, H26.

Keywords: tax avoidance, presumptive taxation, redistribution, occupational choice.

\author{
Alessandro Balestrino \\ University of Pisa \\ Department of Economic Sciences \\ Via Serafini 3 \\ 56126 Pisa \\ Italy \\ balestrino@sp.unipi.it
}

\author{
Umberto Galmarini \\ Catholic University of Milan \\ Institute for Economics and Finance \\ Largo Gemelli 1 \\ 20123 Milan \\ Italy \\ umberto.galmarini@unicatt.it
}

Both authors gratefully acknowledge financial support from MIUR. 


\section{Introduction}

Several governments across the world have relied in the recent past and still rely today on various forms of presumptive taxation, in which indirect methods are used for evaluating the effective tax base and computing the corresponding tax liability. ${ }^{1}$ Basically, the effective tax base is estimated using a set of variables that are strongly correlated with it, and are easily observable, but at the same time cannot be tampered with by the taxpayers; for example, the type of occupation, labor costs, telephone and electricity bills, the number of employees, the size of the store, and so on.

Remarkably, countries with very diverse backgrounds have used these methods: the list includes France, Israel, Italy and the Netherlands, some large Latin American countries (Argentina, Chile and Colombia), countries in Sub-Saharan Africa, as well as in Central and Eastern Europe (Albania, Hungary, Macedonia and Poland, among others) - see Tanzi and Casanegra (1989), Taube and Tadesse (1996), Harrison (1997), Cnossen and Bovenberg (2001). Sometimes (typically in the more developed countries), presumptive taxes are used whenever income is difficult to ascertain, e.g. for small individual firms or in the agricultural sector, and act alongside a proper income tax; sometimes (mostly in developing and transition countries) they fully replace the conventional tax structures. Unfortunately, there is no abundance of hard data which allow us to assess the relative importance of presumptive taxation, but what little evidence we have or may infer seems to suggest that it does not play a minor role: for example, in Italy up to $13 \%$ of reported income might in fact be presumptive income. ${ }^{2}$

Normally, presumptive taxes are conceived as a rough but effective way of raising revenue whenever the government lacks the capability of properly administering an income tax. Since imperfect tax compliance is a sizeable phenomenon not only in the developing but also in the

\footnotetext{
${ }^{1}$ Strictly speaking, all taxes are presumptive, since "(t)he conceptually pure tax base ... cannot be perfectly measured, and the tax authority is constrained to rely on some correlate of the concept." (Slemrod and Yitzhaki, 2002, p. 1457). However, there are cases in which the correlate is immediately found and others in which the gap to bridge is relatively large.

${ }^{2}$ This estimate is based on data available from the Italian Treasury site on http://www.finanze.it/ comunicare/2002/dichiarazioni_99/tabelle/tab102.htm) and concerns the Personal Income Tax (IRPEF) returns for the 1999 fiscal year. According to our computations, about $13.3 \%$ of reported income comes from professionals, single entrepreneurs and unincorporated firms. These kind of taxpayers are dispensed from tax audits if they report earnings at least as high as a "presumptive" income level (which is computed as a percentage of input costs). In fact, virtually all of them report, and are taxed on the basis of, this presumptive income, which is quite lower than their actual earnings in normal years.
} 
transition and OECD economies, it is no surprise that the usage of presumptive taxes is so widespread. In a recent world survey of the shadow economy, Schneider and Enste (2002) argue that during the 90's the average size of the underground sector was $12 \%$ of GDP for OECD countries, $23 \%$ for transition countries and 39\% for developing countries. Andreoni et al. (1998) report that, according to the IRS, in the USA $17 \%$ the income tax is not paid and about $40 \%$ of families underpay their taxes. An additional concern is that the ability to dodge taxes is not equally distributed among taxpayers. For example, small business may find it easier not to comply with their tax obligations than large corporations; public employees have a much harder time at trying to cheat the government than employees of minor firms who can receive "black" payments for, say, extra-time. The conventional strategies of increasing the penalties for tax evasion and/or the frequency and the quality of tax audits, or by reforming the tax code so as to reduce the opportunities of exploiting the so called "tax loopholes" do not always work. ${ }^{3}$ They may be too costly, or simply they may be ineffective: a sale "under the counter" for cash does not leave any direct evidence in the accounting books. Hence the recourse to presumptive taxes.

Here, we are interested in the question whether presumptive taxes can be used to collect revenue in an equitable way and to perform some redistribution. ${ }^{4}$ An answer in the affirmative would definitely raise their status from rough revenue-rasing devices to more sophisticated redistributive instruments, and might remove many objections to their use. To study this issue, we employ an occupational choice model in which two kinds of taxpayers exist: entrepreneurs and workers. It is assumed that both types of individuals can dodge conventional income taxes, although the ability to do so varies with the occupation. In this setup, presumptive taxes may be based on occupational choice: ${ }^{5}$ fixed lump-sum tax payments, or licence fees, differentiated according to the type of occupation, are widely used in Central and Eastern Europe (Azerbaijan, Albania and Hungary, among others) — see Harrison (1997); in Italy, there is a standard income tax allowance conditional on occupational choice, which is smaller for self-employed individuals.

\footnotetext{
${ }^{3}$ See Slemrod (1994) for an analysis of optimal income taxation with tax enforcement.

${ }^{4}$ Previous contributions on presumptive taxation, such as Bennet (1987), Sadka and Tanzi (1993) and Slemrod and Yitzhaki (1994), focus on different aspects of the problem than those addressed in this paper.

${ }^{5}$ Another kind of presumptive taxation which is used in some countries (e.g. France, Israel, Italy, Azerbaijan and Poland) is that based on physical inputs or on input costs (e.g. the number of employees or the wage bill). We study this variety of presumptive taxes in a companion paper (Balestrino and Galmarini, 2002), using a slightly different model - see also fn. 14 below.
} 
We assess the desirability of introducing lump-sum presumptive taxes by means of small revenueneutral reforms, and find that in a number of cases they are indeed capable of performing some redistribution.

The present note is outlined as follows. In section 2 we illustrate the model. Section 3 deals with presumptive lump-sum taxation based on occupational choice. Section 4 offers some concluding remarks.

\section{An occupational choice model ${ }^{6}$}

Consider a large population of individuals whose size is normalized to unity. Each individual is identified by a parameter $n$ representing ability; we take $n$ to be a continuous variable uniformly distributed $^{7}$ over the $[l, h]$ interval, $0 \leq l<h, N=h-l$. Importantly, $n$ is private information. Each agent can choose among two options: to become an entrepreneur (e) or to become a worker $(\mathbf{w})$. An individual that chooses e hires $s>0$ efficiency units of labor at a wage rate $w$, in order to produce $s n$ units of a consumption good. Her gross income is $s(n-w)$, where $s n$ represents revenue (the output price is normalized to unity) and $s w$ represents labor costs. An individual that chooses w supplies $n$ efficiency units of labor in the labor market; hence his income is wn. There is no labor-leisure choice on the part of both entrepreneurs and workers. Also, shifting between occupations is costless.

Within this simple model, there are two possible tax bases that the government can use for redistributive purposes: income and occupational choice. As regards income, tax authorities have no direct knowledge of the skill level $n$, and hence of the income, of both workers and entrepreneurs. Thus income taxation must rely on reported income, which may differ from actual income. As a result, agents will engage in tax avoidance, ${ }^{8}$ i.e. will not report their actual income level, so as to gain a more favorable tax treatment. Income taxation is restricted to be linear. However, as tax authorities are assumed to observe the occupational choice (e or w) of each individual, they can, in principle, make taxes conditional on occupation. This is a very

\footnotetext{
${ }^{6}$ The present framework is based on Balestrino and Galmarini (2002), where we adapt a model originally due to Boadway et al. (1991) to the case of imperfect tax compliance.

${ }^{7}$ The assumption is for expositional convenience. The model can readily be extended to other distributions of the parameter $n$.

${ }^{8}$ We represent tax dodging as tax avoidance (a costly but riskless activity) rather that tax evasion (a risky activity). This keeps the model simple without any major effect on the results. On the relationship between the two representations of imperfect tax compliance, see Cowell (1990a, 1990b) and Balestrino and Galmarini (2003).
} 
simple form of presumptive taxation that assesses the ability to pay not only on the basis of income, but also on the type of occupation.

Let $y^{\mathbf{i}}, \mathbf{i} \in\{\mathbf{w}, \mathbf{e}\}$, be net income (consumption) associated to option $\mathbf{i}$. The following assumption characterizes agents' preferences.

Assumption 1 (i) If $y^{\prime \mathbf{i}}>y^{\prime \prime \mathbf{i}}, \mathbf{i} \in\{\mathbf{w}, \mathbf{e}\}$, then $y^{\prime \mathbf{i}} \succ y^{\prime \prime \mathbf{i}}$. (ii) If $y^{\mathbf{i}}>y^{\mathbf{j}}, \mathbf{i}, \mathbf{j} \in\{\mathbf{w}, \mathbf{e}\}, \mathbf{i} \neq \mathbf{j}$, then $y^{\mathbf{i}} \succ y^{\mathbf{j}}$. (iii) If $y^{\mathbf{w}}=y^{\mathbf{e}}$, then $y^{\mathbf{w}} \succ y^{\mathbf{e}}$.

A1(i) simply says that, within each option, a higher income is preferred to a lower one. A1(ii) says that whenever two options give a different income then the one with the higher income is preferred. A1(iii) strikes a choice whenever the two options give the same income: for equal income, $\mathbf{w}$ is preferred to $\mathbf{e}$ (but, nothing of substance changes if we make the opposite assumption). ${ }^{9}$

To define entrepreneurs' net income, let $a^{\mathbf{e}} \in[0,1]$ be the fraction of avoided income. Tax avoidance costs are assumed to be linear in gross income: the per-unit-of-gross-income taxavoidance-costs, $c^{\mathbf{e}}\left(a^{\mathbf{e}}\right)$, depend on the fraction of concealed income. ${ }^{10} c^{\mathbf{e}}($.$) satisfies the follow-$ ing restrictions (throughout the paper, subscripts denote derivatives):

Assumption 2 (i) $c^{\mathbf{e}}(0)=0, c^{\mathbf{e}}>0$ for $a^{\mathbf{e}}>0$. (ii) $c_{a}^{\mathbf{e}}(0)=0, c_{a}^{\mathbf{e}}>0$ for $a^{\mathbf{e}}>0, c_{a a}^{\mathbf{e}}>0$, $c_{a}^{\mathbf{e}}(1) \geq 1$.

A2(i): Full reporting is costless, whereas tax avoidance is always costly. A2(ii): The marginal cost of concealing the first unit of income is zero; then the marginal cost is positive and increasing in the level of concealed income; the marginal cost of concealing the last unit of income is greater than or equal to one.

Provided that $n-w \geq 0,{ }^{11}$ the net income of a type- $n$ entrepreneur is thus equal to:

$$
\alpha-\beta+\left[1-t+t a^{\mathbf{e}}-c^{\mathbf{e}}\left(a^{\mathbf{e}}\right)\right] s(n-w),
$$

\footnotetext{
${ }^{9}$ The assumption is innocuous. Since the productivity parameter is distributed on a continuous interval, the probability that an agent is indifferent between the two occupations is zero.

${ }^{10}$ Let $\pi=s(n-w)$. The standard way of modelling tax avoidance costs, see Slemrod (2001), is to posit a cost of avoidance function $C(A, \pi)$, where $A=a \pi$ is the amount of concealed income. If one assumes that $C($.) is homogeneous of degree one in $A$ and $\pi$, then it is possible to define a per-unit-of-gross-income tax-avoidancecost as $c(a) \equiv C(a, 1)$. The homogeneity assumption, which means that the tax avoidance technology exhibits constant returns to scale, is also made by Boadway et al. (1994).

${ }^{11}$ Since we assume that losses are not subsidized at the margin, we may take it that a type- $n$ individual never chooses e whenever $n-w<0$.
} 
where $\beta$ is the occupation-based lump sum tax levied on entrepreneurs (a subsidy when negative), $t \in[0,1]$ is the marginal income tax rate on entrepreneurs and $\alpha$ is a universal lump-sum subsidy. ${ }^{12}$ By A1(i), tax avoidance is chosen by maximizing net income with respect to $a^{\mathbf{e}}$ (entrepreneurs are price-takers on the labor market). The first order condition for an interior solution is $t=c_{a}^{\mathbf{e}}$, that can be solved for the optimal $a^{\mathbf{e}}$. Let $\hat{a}^{\mathbf{e}}(t)$ be the optimal choice for $a^{\mathbf{e}}$ and let $\hat{c}^{\mathbf{e}}=c^{\mathbf{e}}\left(\hat{a}^{\mathbf{e}}\right)$.

To shorten notation, let $\hat{\theta}^{\mathbf{e}} \equiv 1-t+t \hat{a}^{\mathbf{e}}-\hat{c}^{\mathbf{e}}$. With $a^{\mathbf{e}}$ optimally chosen, net income associated to $\mathbf{e}$ is thus $y^{\mathbf{e}}=\alpha-\beta+\hat{\theta}^{\mathbf{e}} s(n-w)$. It is not difficult to prove a few results that we will use later on. We have that tax avoidance is zero when income is not taxed at the margin, and positive when taxed; that $100 \%$ tax avoidance never occurs, unless $t=1$ and $c_{a}^{\mathbf{e}}(1)=1$; that the proportion of avoided income is increasing in the tax rate and, finally, that the effective marginal tax rate, $t-t \hat{a}^{\mathbf{e}}+\hat{c}^{\mathbf{e}}$, is smaller than the statutory tax rate, $t$. Formally:

Lemma 1 Under A2: (i) $\hat{a}^{\mathbf{e}}(0)=0, \hat{a}^{\mathbf{e}} \in(0,1)$ for $t \in(0,1), \hat{a}^{\mathbf{e}}(1) \leq 1$. (ii) $\hat{a}_{t}^{\mathbf{e}}=1 / \hat{c}_{a a}^{\mathbf{e}}>0$ (iii) $t \hat{a}^{\mathbf{e}} \geq \hat{c}^{\mathbf{e}}, \hat{\theta}^{\mathbf{e}}>0$ for all $t$. (iv) $\hat{\theta}_{t}^{\mathbf{e}}=-\left(1-\hat{a}^{\mathbf{e}}\right)$.

Proof. Part (i) comes directly from A2(ii) and $t=c_{a}^{\mathbf{e}}$. Part (ii) comes from totally differentiating $t-c_{a}^{\mathbf{e}}=0$ and using A2(ii). Part (iii) comes from the fact that, if $t>0$ then $\int_{0}^{\hat{a}^{\mathbf{e}}}\left[t-c_{a}^{\mathbf{e}}\right] \mathrm{d} a^{\mathbf{e}}=t \hat{a}^{\mathbf{e}}-c^{\mathbf{e}}\left(\hat{a}^{\mathbf{e}}\right)>0$, since $t>c_{a}^{\mathbf{e}}$ for $a^{\mathbf{e}} \in\left[0, \hat{a}^{\mathbf{e}}\right)$; if $t=0$ then $\hat{a}^{\mathbf{e}}=\hat{c}^{\mathbf{e}}=0$. Hence $\hat{\theta}^{\mathbf{e}}>0$, since $(1-t)>0$ for $t<1$ and $\left(t \hat{a}^{\mathbf{e}}-\hat{c}^{\mathbf{e}}\right)>0$ for $t>0$. Part (iv) comes from the envelope theorem, by which $\hat{\theta}_{t}^{\mathbf{e}}=-1+\hat{a}^{\mathbf{e}}+\left(t-\hat{c}_{a}^{\mathbf{e}}\right) \hat{a}_{t}^{\mathbf{e}}=-1+\hat{a}^{\mathbf{e}}$, since $t=\hat{c}_{a}^{\mathbf{e}}$.

A type- $n$ worker net income is equal to

$$
\alpha+\left[1-\tau+\tau a^{\mathbf{w}}-c^{\mathbf{w}}\left(a^{\mathbf{w}}\right)\right] w n,
$$

where $a^{\mathbf{w}} \in[0,1]$ is the fraction of avoided income, $c^{\mathbf{w}}($.$) are the unit tax avoidance costs, and$ $\tau \in[0,1]$ is the marginal income tax rate on workers. Note that we assumed that avoidance costs vary between workers and entrepreneurs; this is a simple way of reflecting a natural dispersion of opportunities for tax dodging across the population (see the Introduction). At this stage, we leave it open whether workers can cheat the government more easily than entrepreneurs or the other way round. For the sake of generality, we also took the tax rates to be (in principle) differentiated; we will notice when necessary the cases in which setting $t=\tau$ makes a difference

\footnotetext{
${ }^{12}$ The occupation-based lump sum $\operatorname{tax} \beta$ is not deductible from the income tax base, but, as it is immediate to show, the alternative assumption (deductibility) would not affect the results.
} 
for policy analysis. Finally, there is no occupation-based lump sum tax/subsidy on workers. This restriction is without loss of generality; as we will see from the arbitrage equation (1) below, an increase in a workers' lump sum tax would be actually equivalent to a reduction of entrepreneurs' lump sum tax $\beta$.

Tax avoidance is chosen by workers by maximizing net income with respect to $a^{\mathbf{w}}$. Let $\hat{a}^{\mathbf{w}}(\tau)$ be the optimal choice for $a^{\mathbf{w}}$ and let $\hat{c}^{\mathbf{w}}=c^{\mathbf{w}}\left(\hat{a}^{\mathbf{w}}\right)$ and $\hat{\theta}^{\mathbf{w}} \equiv 1-\tau+\tau \hat{a}^{\mathbf{w}}-\hat{c}^{\mathbf{w}}$. With $a^{\mathbf{w}}$ optimally chosen, net income associated to $\mathbf{w}$ is thus $y^{\mathbf{w}}=\alpha+\hat{\theta}^{\mathbf{w}} w n$. Regarding $c^{\mathbf{w}}($.$) , we use$ the same set of assumptions introduced for $c^{\mathbf{e}}($.$) :$

Assumption $3(\mathbf{i}) c^{\mathbf{w}}(0)=0, c^{\mathbf{w}}>0$ for $a^{\mathbf{w}}>0$. (ii) $c_{a}^{\mathbf{w}}(0)=0, c_{a}^{\mathbf{w}}>0$ for $a^{\mathbf{w}}>0, c_{a a}^{\mathbf{w}}>0$, $c_{a}^{\mathbf{w}}(1) \geq 1$.

Hence, results similar to those derived for entrepreneurs hold for tax avoidance behavior by workers:

Lemma 2 Under A3: (i) $\hat{a}^{\mathbf{w}}(0)=0, \hat{a}^{\mathbf{w}} \in(0,1)$ for $\tau \in(0,1), \hat{a}^{\mathbf{w}}(1) \leq 1$. (ii) $\hat{a}_{\tau}^{\mathbf{w}}=1 / \hat{c}_{a a}^{\mathbf{w}}>0$ (iii) $\tau \hat{a}^{\mathbf{w}} \geq \hat{c}^{\mathbf{w}}, \hat{\theta}^{\mathbf{w}}>0$ for all $\tau$. (iv) $\hat{\theta}_{\tau}^{\mathbf{w}}=-\left(1-\hat{a}^{\mathbf{w}}\right)$.

We are now ready to define occupational choices. These are governed by the following arbitrage equation:

$$
y^{\mathbf{e}} \equiv \alpha-\beta+\hat{\theta}^{\mathbf{e}} s\left(n^{*}-w\right)=\alpha+\hat{\theta}^{\mathbf{w}} w n \equiv y^{\mathbf{w}},
$$

where $n^{*}$ is the marginal skill. This condition establishes that the net income of the marginal workers (the most able among them) must equal the net income of the marginal entrepreneurs (the least skilled). Thus, by A1(ii) and A1(iii), those individuals whose ability goes from $l$ to $n^{*}$ (included) choose $\mathbf{w}$, while those whose ability goes from $n^{*}$ (excluded) to $h$ choose $\mathbf{e}^{13}$

The market clearing equation is written:

$$
\int_{l}^{n^{*}} n \mathrm{~d} n=\int_{n^{*}}^{h} s \mathrm{~d} n
$$

where the l.h.s. represents total labor supply, and the r.h.s. total labor demand.

\footnotetext{
${ }^{13}$ The separation between high-ability agents (who become entrepreneurs) and low-ability agents (who become workers), while analytically extremely convenient, is not a general property of the sort of occupational model we employ here. Boadway et al. (1994, fn. 4) discuss alternative sufficient conditions under which the separation occurs, one of which is that production can be written (in our notation) as $n k(s)$ where $k$ is a concave function. Since our production function is simply $n s$, the condition is satisfied.
} 
Eqs. (1) and (2) determine the equilibrium value of the marginal skill, $\tilde{n}^{*}$, and the equilibrium wage rate, $\tilde{w}$, as a function of the policy variables,

$$
\begin{aligned}
& \tilde{n}^{*}=\sqrt{s^{2}+l^{2}+2 s h}-s, \\
& \tilde{w}=\frac{-\beta+\hat{\theta}^{\mathbf{e}} s \tilde{n}^{*}}{\hat{\theta}^{\mathbf{e}} s+\hat{\theta}^{\mathbf{w}} \tilde{n}^{*}} .
\end{aligned}
$$

It is immediate to see that $\tilde{n}^{*} \in(l, h)$ for all $s>0$. As for the equilibrium wage rate, we consider only triples of the tax parameters $\beta, \tau$ and $t$ ( $\tilde{w}$ is independent of $\alpha$ ) ensuring that $\tilde{w} \geq 0$ and $\tilde{n}^{*}-\tilde{w} \geq 0$ :

Definition 1 The set of admissible tax policies is defined by

$$
\mathcal{T}=\left\{t \in[0,1], \tau \in[0,1], \alpha \in \Re, \beta \in \Re \text { such that } 0 \leq \tilde{w} \leq \tilde{n}^{*}\right\} .
$$

As for the impact of tax instruments on the wage rate, from (4) we get (see Appendix A.1 for the details):

$$
\begin{aligned}
& \tilde{w}_{\beta}=-\left(\hat{\theta}^{\mathbf{e}} s+\hat{\theta}^{\mathbf{w}} \tilde{n}^{*}\right)^{-1}<0, \\
& \tilde{w}_{\tau}=-\left(1-\hat{a}^{\mathbf{w}}\right) \tilde{n}^{*} \tilde{w} \tilde{w}_{\beta}>0, \\
& \tilde{w}_{t}=\left(1-\hat{a}^{\mathbf{e}}\right) s\left(\tilde{n}^{*}-\tilde{w}\right) \tilde{w}_{\beta}<0 .
\end{aligned}
$$

The intuition is straightforward. For a given wage rate, an increase in $\beta$ or in $t$ would result in an excess of labor supply as some entrepreneurs (the least skilled among them) would now prefer to shift to a salaried job; $\tilde{w}$ thus lowers so as to clear the labor market. A reversed line of arguments holds for an increase in $\tau$.

For later use, it is useful to define the following variables. Let the fraction of workers be $q^{\mathbf{w}}=\left(\tilde{n}^{*}-l\right) N^{-1}$, and let their mean skill level be $\bar{n}^{\mathbf{w}}=\left(\tilde{n}^{*}-l\right)^{-1} \int_{l}^{\tilde{n}^{*}} n \mathrm{~d} n$. Similarly, define $q^{\mathbf{e}}=\left(h-\tilde{n}^{*}\right) N^{-1}$ and $\bar{n}^{\mathbf{e}}=\left(h-\tilde{n}^{*}\right)^{-1} \int_{\tilde{n}^{*}}^{h} n \mathrm{~d} n$.

\section{Presumptive lump-lum taxation}

Suppose that the government's objective is represented by a concave social welfare function

$$
W=\int_{l}^{\tilde{n}^{*}} g\left(y^{\mathbf{w}}\right) \mathrm{d} n+\int_{\tilde{n}^{*}}^{h} g\left(y^{\mathbf{e}}\right) \mathrm{d} n,
$$

where $g(\cdot)$ is increasing and concave; in the special case when $g(y) \equiv y$ we have a utilitarian objective. Since the income distribution in the laissez-faire economy is unequal, there is a case for intervention on equity grounds. 
Consider then an economy in which the linear income tax rates, $(\tau, t)$, are fixed at some arbitrary level - including possibly $(0,0)$. Using these conventional instruments, the government will generally be able, within each group, to tax more heavily those who earn a higher income. However, the presence of tax avoidance will impair the government's capability to redistribute income using the income tax. Indeed, we saw from Lemmas 1 and 2 that the effective marginal tax rates are lower than the statutory tax rates, which makes the tax schedule less progressive in practice than it appears to be; moreover, taxpayers waste resources when engaging in the tax avoidance activity. Also, entrepreneurs and workers differ in their capability to hide the tax base, which makes redistribution across groups via income taxation even less effective.

To investigate the usefulness of presumptive taxation as an equitable policy tool, we adopt the reform approach. Hence, we consider small welfare-improving revenue-neutral reforms, whereby the policy instruments are infinitesimally adjusted in such a way that the government budget constraint is not violated, but social welfare has increased. It is well-known that it is formally equivalent to work either with the resource constraint or with the revenue constraint. In our case, it is easier to work with the former. Then, we have that the exogenous revenue target $\bar{R}$ equals total output less total disposable income and less the total cost of avoidance (see Appendix A.2 for the details):

$$
\frac{1}{N}\left\{\int_{\tilde{n}^{*}}^{h} s n \mathrm{~d} n-\int_{l}^{\tilde{n}^{*}} \tilde{y}^{\mathbf{w}} \mathrm{d} n-\int_{\tilde{n}^{*}}^{h} \tilde{y}^{\mathbf{e}} \mathrm{d} n-\int_{l}^{\tilde{n}^{*}} \hat{c}^{\mathbf{w}} \tilde{w} n \mathrm{~d} n-\int_{\tilde{n}^{*}}^{h} \hat{c}^{\mathbf{e}} s(n-\tilde{w}) \mathrm{d} n\right\}=\bar{R},
$$

where $\tilde{y}^{\mathbf{w}}$ and $\tilde{y}^{\mathrm{e}}$ denote equilibrium net incomes:

$$
\begin{aligned}
& \tilde{y}^{\mathbf{w}}=\alpha+\hat{\theta}^{\mathbf{w}} \tilde{w} n, \quad n \in\left[l, \tilde{n}^{*}\right], \\
& \tilde{y}^{\mathbf{e}}=\alpha-\beta+\hat{\theta}^{\mathbf{e}} s(n-\tilde{w}), \quad n \in\left(\tilde{n}^{*}, h\right] .
\end{aligned}
$$

We now look for a small reform $(d \alpha, d \beta)$ in which an increase (decrease) in the presumptive tax levied on entrepreneurs $(d \beta)$ is matched with an increase (decrease) in the lump-sum universal subsidy $(d \alpha)$ so as to leave the government budget (the resource constraint) unaffected and at same time raise social welfare.

Using (5), the derivatives of (10) and (11) with respect to $\alpha$ and $\beta$ are:

$$
\begin{aligned}
& \tilde{y}_{\alpha}^{\mathbf{w}}=\tilde{y}_{\alpha}^{\mathbf{e}}=1, \\
& \tilde{y}_{\beta}^{\mathbf{w}}=\hat{\theta}^{\mathbf{w}} \tilde{w}_{\beta} n, \quad \tilde{y}_{\beta}^{\mathbf{e}}=-\left(1+\hat{\theta}^{\mathbf{e}} \tilde{w}_{\beta}\right)=\hat{\theta}^{\mathbf{w}} \tilde{w}_{\beta} \tilde{n}^{*} .
\end{aligned}
$$

We use these to differentiate the resource contraint (9):

$$
d \alpha+\left(q^{\mathbf{w}} \bar{n}^{\mathbf{w}}+q^{\mathbf{e}} \tilde{n}^{*}\right) \hat{\theta}^{\mathbf{w}} \tilde{w}_{\beta} d \beta+q^{\mathbf{w}} \hat{c}^{\mathbf{w}} \bar{n}^{\mathbf{w}} \tilde{w}_{\beta} d \beta-q^{\mathbf{e}} \hat{c}^{\mathbf{e}} s \tilde{w}_{\beta} d \beta=0,
$$


so that, using (2) to substitute $q^{\mathbf{w}} \bar{n}^{\mathbf{w}}$ for $q^{\mathbf{e}} s$ and solving (14) for $d \alpha$, we get:

$$
\left.d \alpha\right|_{d R=0}=-\hat{\theta}^{\mathbf{w}}\left(q^{\mathbf{w}} \bar{n}^{\mathbf{w}}+q^{\mathbf{e}} \tilde{n}^{*}\right) \tilde{w}_{\beta} d \beta+q^{\mathbf{e}} s\left(\hat{c}^{\mathbf{e}}-\hat{c}^{\mathbf{w}}\right) \tilde{w}_{\beta} d \beta .
$$

Totally differentiating (10) and (11), using (12) and (13), the impact of a revenue-neutral tax reform in terms of agents net incomes is characterized as follows:

$$
\begin{aligned}
\left.d \tilde{y}^{\mathbf{w}}\right|_{(d \alpha, d \beta) \mid d R=0}= & \left.d \alpha\right|_{d R=0}+\hat{\theta}^{\mathbf{w}} \tilde{w}_{\beta} n d \beta= \\
& =-\hat{\theta}^{\mathbf{w}}\left(n^{\circ}-n\right) \tilde{w}_{\beta} d \beta+q^{\mathbf{e}} s\left(\hat{c}^{\mathbf{e}}-\hat{c}^{\mathbf{w}}\right) \tilde{w}_{\beta} d \beta, \quad n \in\left[l, \tilde{n}^{*}\right], \\
\left.d \tilde{y}^{\mathbf{e}}\right|_{(d \alpha, d \beta) \mid d R=0}= & \left.d \alpha\right|_{d R=0}+\hat{\theta}^{\mathbf{w}} \tilde{w}_{\beta} \tilde{n}^{*} d \beta= \\
& =\hat{\theta}^{\mathbf{w}} q^{\mathbf{w}}\left(\tilde{n}^{*}-\bar{n}^{\mathbf{w}}\right) \tilde{w}_{\beta} d \beta+q^{\mathbf{e}} s\left(\hat{c}^{\mathbf{e}}-\hat{c}^{\mathbf{w}}\right) \tilde{w}_{\beta} d \beta, \quad n \in\left(\tilde{n}^{*}, h\right],
\end{aligned}
$$

where $n^{\circ} \equiv \bar{n}^{\mathbf{w}}+q^{\mathbf{e}}\left(\tilde{n}^{*}-\bar{n}^{\mathbf{w}}\right)$, with $l<n^{\circ}<\tilde{n}^{*}$. The first term in both (16) and (17) captures the redistributive impact of the tax reform, whereas the second term in both expressions identical for all agents - reflects the impact on the efficiency loss associated with the avoidance costs.

\subsection{Presumptive taxes as a substitute for conventional taxes}

If there is no income taxation, we have $t=\tau=0$ and therefore $\hat{c}^{\mathbf{e}}=\hat{c}^{\mathbf{w}}=0$, hence the second term in both (16) and (17) vanishes. In this case, presumptive taxation has only a redistribution effect (recall that we have no labour-leisure choice). It is immediate to see that a tax reform such that $d \beta>0$ has a negative impact on entrepreneurs' net income, since $\tilde{w}_{\beta}<0$ and $\tilde{n}^{*}>\bar{n}^{\mathbf{w}}$; the loss is the same in absolute size for all entrepreneurs. The reform has however a positive impact on the poorest among workers, namely those with ability $n<n^{\circ}$; the absolute gain is decreasing in $n$, and is zero for those with $n=n^{\circ}$. The "rich" workers, those with $n>n^{\circ}$, are instead penalized by the tax reform; the absolute loss is increasing in $n$. Importantly, the three redistributive terms add up to zero in the aggregate, since, as can be easily seen:

$$
-\int_{l}^{\tilde{n}^{*}}\left(n^{\circ}-n\right) \mathrm{d} n+\int_{\tilde{n}^{*}}^{h} q^{\mathbf{w}}\left(\tilde{n}^{*}-\bar{n}^{\mathbf{w}}\right) \mathrm{d} n=0 .
$$

Hence, (18) tells us that, without income taxation,

$$
\left.\int_{l}^{\tilde{n}^{*}} d \tilde{y}^{\mathbf{w}}\right|_{(d \alpha, d \beta) \mid d R=0} \mathrm{~d} n+\left.\int_{\tilde{n}^{*}}^{h} d \widetilde{y}^{\mathbf{e}}\right|_{(d \alpha, d \beta) \mid d R=0} \mathrm{~d} n=0 .
$$

Given its lump-sum nature, the occupation-based presumptive tax system purely redistributes income among the citizens. Hence, a utilitarian planner would reject a tax reform involving 
an increase in $\beta$, because there is no efficiency gain to be reaped - (19) is exactly the social welfare change induced by the tax reform when the government is utilitarian. However, a reform such that $d \beta>0$ would be welfare improving for any kind of strictly concave welfare function, since the government values the increase in the net income of the poor workers more than the income losses incurred by the middle-earners (workers with ability above $n^{\circ}$ ) and high-earners (entrepreneurs) - this follows from the concavity of $g(\cdot)$.

So far we have characterised a local result, but we can also easily identify the optimal $\beta$, which is simply the value of $\beta$ that brings to zero the wage rate: indeed, the redistributive terms in (16) and (17) are independent of $\beta$, therefore they call for a corner solution, the largest admissible value of $\beta$. Summing up:

Proposition 1 In the absence of income taxation, a revenue-neutral tax reform such that $d \beta>$ 0 is welfare improving for any strictly concave social welfare function. The optimal $\beta$ is such that $\tilde{w}=0$, i.e. $\beta=s \tilde{n}^{*}$.

Proposition 1 strikes a point in favour of presumptive taxation in a very sharp way. Whenever conventional income taxes cannot be used, which is a common situation in many transition and developing economies, the government has at its disposal a simple and effective way of achieving some redistribution, namely setting up a presumptive tax system based on occupational choices, in which entrepreneurs are taxed. The intuition is obvious: the differences in occupational status proxy the differences in income and thus shifting the tax burden towards the entrepreneurs/high income agents is good for welfare whenever the government has a redistributive objective. Morevoer, the presumptive tax redistributes not only between occupational groups, but also within the workers's group in favour of the less well-off.

\subsection{Presumptive taxes as a complement to conventional taxes}

What happens when also the more conventional income taxes are being used? The subsequent analysis shows that, for arbitrary values of the income tax rates, there is a wide range of cases in which a presumptive tax system improves redistribution. With income taxation, in addition to the redistribution terms in (16) and (17), we need to take note of the efficiency term $q^{\mathbf{e}} s\left(\hat{c}^{\mathbf{e}}-\hat{c}^{\mathbf{w}}\right) \tilde{w}_{\beta}$, which, we recall, is the same for all agents $-\hat{c}^{\mathbf{e}}$ and $\hat{c}^{\mathbf{w}}$ depend only on the tax rates. It is easy to see that the sign of the efficiency term depends on the difference between the unit cost of avoidance for the two occupational groups. If $\hat{c}^{\mathbf{e}}=\hat{c}^{\mathbf{w}}$, i.e. agents from the two groups waste in equilibrium the same amount of resources for each unit of income hidden 
from tax authorities, there is no efficiency gain from presumptive taxation. The same analysis as before applies; so, for example, if $t=\tau$, and, importantly, the avoidance cost functions are the same for entrepreneurs and workers, it is desirable to set $d \beta>0$.

If $\hat{c}^{\mathbf{e}}<\hat{c}^{\mathbf{w}}$, the term is positive (since $\tilde{w}_{\beta}<0$ ), hence, a tax reform involving $d \beta>0$ will improve the welfare of everybody via an efficiency gain, because it reduces the amount of resources wasted by the tax avoidance efforts. The key to this result is that an increase in $\beta$ causes, as we know from the comparative statics, a reduction in the wage rate; therefore, the gross incomes of the workers decrease, while those of the entrepreneurs (for whom wages represent costs) increase. Thus, there is redistribution, in terms of gross incomes, towards the group whose tax avoidance behaviour is less costly to society. In this event, there will be a larger group of agents benefiting from a reform such that $d \beta>0$, relative to the case in which the efficiency term is absent; not only the poor workers $\left(n<n^{\circ}\right)$, but also (some of the) rich workers and maybe the entrepreneurs may enjoy an increase in their net income, if the efficiency effect is large enough to offset the equity effect. Indeed, if $\hat{c}^{\mathbf{e}}$ is sufficiently smaller than $\hat{c}^{\mathbf{w}}$, then the reform may turn out to be Pareto-improving, as (16) and (17) may be positive for all $n$.

If $\hat{c}^{\mathbf{e}}>\hat{c}^{\mathbf{w}}$, the opposite holds: from an efficiency point of view, it is desirable to set $d \beta<0$. Thus, a reform such that $d \beta>0$ will be desirable only if the government is strongly inequalityaverse and the efficiency loss is small enough to avoid offsetting the redistributive gain for low-earners. On the other hand, if the efficiency gain from setting $d \beta<0$ is sufficiently large, it may in principle happen that the reform is Pareto-improving.

Take for example the extreme case of a Rawlsian planner, for whom only the welfare of those at the bottom of the income distribution matters: using (16), the impact of tax reforms on the net income of the poorest individuals, $n=l$, can easily seen to be:

$$
\left.d \tilde{y}^{\mathbf{w}}\right|_{(d \alpha, d \beta) \mid d R=0}=-\left[\hat{\theta}^{\mathbf{w}}\left(n^{\circ}-l\right)-q^{\mathbf{e}} s\left(\hat{c}^{\mathbf{e}}-\hat{c}^{\mathbf{w}}\right)\right] \tilde{w}_{\beta} d \beta=-B(l) \tilde{w}_{\beta} d \beta .
$$

A revenue-neutral tax reform $d \beta>0$ improves the welfare of poorest individuals if the term in square brackets, $B(l)$, is positive; a sufficient condition for this is $\hat{c}^{\mathbf{e}} \leq \hat{c}^{\mathbf{w}}$. In the case of a Ralwsian objective, such a reform is therefore welfare-improving; actually, from (18) we can conclude that the same holds true for any concave social welfare function.

The condition $\hat{c}^{\mathbf{e}} \leq \hat{c}^{\mathbf{w}}$ is only sufficient, for $B(l)>0$ may hold even if $\hat{c}^{\mathbf{e}}>\hat{c}^{\mathbf{w}}$. In that case, there is a trade-off between efficiency, calling for $d \beta<0$, and equity, calling for $d \beta>0$. For the Rawlsian planner, a revenue-neutral tax reform with $d \beta>0$ continues to be welfare 
improving; the result does not generalise however to all concave social welfare function, as a strong degree of inequality aversion is needed. Indeed, if inequality aversion is weak or absent (utilitarianism), a welfare-improvement is achieved by setting $d \beta<0$.

Finally, when $\hat{c}^{\mathbf{e}}>\hat{c}^{\mathbf{w}}$ and $B(l)<0$, both efficiency and equity call for a subsidy, hence a revenue-neutral tax reform such that $d \beta<0$ is welfare improving in the case of a Ralwsian objective; indeed, it is Pareto-improving, since if the term in brackets is negative for $n=l$, it must be negative also for all other values of $n$. Summing up:

Proposition 2 For any given $t \in[0,1], \tau \in[0,1]$,

- If $\hat{c}^{\mathbf{e}} \leq \hat{c}^{\mathbf{w}}$ a revenue-neutral tax reform such that $d \beta>0$ is welfare-improving for any concave social welfare function. If $\hat{c}^{\mathbf{e}} \leq \hat{c}^{\mathbf{w}}$ and $\left.d \tilde{y}^{\mathbf{e}}\right|_{(d \alpha, d \beta) \mid d R=0}>0$ (eq. 17) a revenueneutral tax reform such that $d \beta>0$ is Pareto-improving

- If $\hat{c}^{\mathbf{e}}>\hat{c}^{\mathbf{w}}$ and $B(l)>0$, there exists a sufficiently concave social welfare function for which a revenue-neutral tax reform such that $d \beta>0$ is welfare-improving; if the objective function is utilitarian, the welfare-improving reform requires setting $d \beta<0$.

- Finally, if $\hat{c}^{\mathbf{e}}>\hat{c}^{\mathbf{w}}$ and $B(l) \leq 0$, a revenue-neutral tax reform such that $d \beta<0$ is Pareto-improving.

As before, all terms defining the direction of the optimal tax reform are independent of $\beta$; hence, we can immediately get the following global results:

Corollary 1 For any given $t \in[0,1], \tau \in[0,1]$, if $\hat{c}^{\mathbf{e}} \leq \hat{c}^{\mathbf{w}}$ the optimal $\beta$ is such that $\tilde{w}=0$, i.e. $\beta=\hat{\theta}^{\mathbf{e}}$ sñ $\tilde{n}^{*}$, for any concave social welfare function. If $\hat{c}^{\mathbf{e}}>\hat{c}^{\mathbf{w}}$ and $B(l)>0$, there exists a sufficiently concave social welfare function such that $\beta=\hat{\theta}^{\mathbf{e}}$ sñ $^{*}$ is optimal; in the utilitarian case $\beta=-\hat{\theta}^{\mathbf{w}}\left(\tilde{n}^{*}\right)$ is optimal. Finally, if $\hat{c}^{\mathbf{e}}>\hat{c}^{\mathbf{w}}$ and $B(l) \leq 0$, the Pareto-efficient $\beta$ is such that $\tilde{n}^{*}-\tilde{w}=0$, i.e. $\beta=-\hat{\theta}^{\mathbf{w}}\left(\tilde{n}^{*}\right)^{2}$.

As we can see, it is generally the case that an occupation-based lump-sum presumptive tax system ameliorates welfare, sometime for all members of the community, sometimes only if the government is sufficiently inequality averse. The usefulness of this form of taxation is confirmed no matter the levels at which the marginal tax rates are set, and no matter which group wastes more resources in tax avoidance. Perhaps somewhat strikingly, it might happen that the reform involves subsidising the entrepreneurs, who are at the top of the income distribution; if for 
example we take the extreme, although not unreasonable view that workers cannot avoid the income tax (so that in equilibrium $\hat{c}^{\mathbf{w}}=0$ ), while entrepreneurs can, the efficiency term may be indeed large enough to obtain $B(l)<0$. If that is the case, a presumptive subsidy for highearning businessmen improves the welfare of all by exploiting the market-induced adjustment of the wage rate; importantly, this holds for all admissible values of the marginal income tax rates. $^{14}$

\section{Conclusions}

In several developing and transition as well as developed countries, citizens can escape their tax obligations. This may severely limit the redistributive action of the governments. One of the possible responses to that problem is for the governments to engage in some form of presumptive taxation. In this paper, we have argued that presumptive taxation may indeed be a useful instrument for raising the welfare of the less well-off and sometimes of all citizens, although it may achieve this outcome in a somewhat unexpected fashion. Indeed, we saw that there are circumstances in which the entrepreneurs, who are at the top of the income distribution, have to be subsidized in order to achieve an improvement of the workers' welfare. The reason why this occurs is that presumptive taxes have not only a redistributive action, but also affect efficiency through the amount of resources devoted to tax avoidance. Our occupational choice model can indeed capture the general equilibrium effects of taxation, and we are therefore able to show that presumptive taxes (as opposed to subsidies) can under certain circumstances increase aggregate avoidance costs, thereby reducing their usefulness as redistributive devices. Several authors, including Kaplow (1996), have emphasized that the interaction between market forces and taxation is crucial for understanding the effect of the latter in the presence of tax avoidance. Ours is basically an attempt at taking a step in that direction, and we hope therefore that the present paper has some value as a methodological contribution as well as for its specific results.

\footnotetext{
${ }^{14}$ The case in which only entrepeneures can avoid taxes is studied in Balestrino and Galmarini (2002).
} 


\section{Appendix}

\section{A.1 Comparative statics}

Derivative $\tilde{w}_{\beta}$ in (5) is obtained immediately from (4). As for $\tilde{w}_{\tau}$, using $\hat{\theta}_{\tau}^{\mathbf{w}}=-\left(1-\hat{a}^{\mathbf{w}}\right)$ from Lemma 2(iv), (5) and (4), one obtains

$$
\tilde{w}_{\tau}=\frac{\left(1-\hat{a}^{\mathbf{w}}\right) \tilde{n}^{*}\left(-\beta+\hat{\theta}^{\mathbf{e}} s \tilde{n}^{*}\right)}{\left(\hat{\theta}^{\mathbf{e}} s+\hat{\theta}^{\mathbf{w}} \tilde{n}^{*}\right)^{2}}=-\left(1-\hat{a}^{\mathbf{w}}\right) \tilde{n}^{*} \tilde{w} \tilde{w}_{\beta} .
$$

Finally, using $\hat{\theta}_{t}^{\mathbf{e}}=-\left(1-\hat{a}^{\mathbf{e}}\right)$ from Lemma 1(iv), (5) and (4), one gets

$$
\tilde{w}_{t}=\frac{-\left(1-\hat{a}^{\mathbf{e}}\right) s \tilde{n}^{*}}{\hat{\theta}^{\mathbf{e}} s+\hat{\theta}^{\mathbf{w}} \tilde{n}^{*}}+\frac{\left(1-\hat{a}^{\mathbf{e}}\right) s\left(-\beta+\hat{\theta}^{\mathbf{e}} s \tilde{n}^{*}\right)}{\left(\hat{\theta}^{\mathbf{e}} s+\hat{\theta}^{\mathbf{w}} \tilde{n}^{*}\right)^{2}}=\left(1-\hat{a}^{\mathbf{e}}\right) s\left(\tilde{n}^{*}-\tilde{w}\right) \tilde{w}_{\beta} .
$$

\section{A.2 The resource constraint}

The government budget constraint is

$$
\frac{1}{N}\left\{\int_{l}^{\tilde{n}^{*}}\left\{-\alpha+\left(1-\hat{a}^{\mathbf{w}}\right) \tau \tilde{w} n\right\} d n+\int_{\tilde{n}^{*}}^{h}\left\{-\alpha+\left(1-\hat{a}^{\mathbf{e}}\right) t s(n-\tilde{w})\right\} d n\right\}=\bar{R} .
$$

Substituting $-\alpha+\left(1-\hat{a}^{\mathbf{w}}\right) \tau \tilde{w} n=-\tilde{y}^{\mathbf{w}}+\left(1-\hat{c}^{\mathbf{w}}\right) \tilde{w} n$ and $-\alpha+\left(1-\hat{a}^{\mathbf{e}}\right) t s(n-\tilde{w})=-\tilde{y}^{\mathbf{e}}+(1-$ $\left.\hat{c}^{\mathbf{e}}\right) s(n-\tilde{w})$ in (A3) one gets

$$
\begin{aligned}
\frac{1}{N}\left\{-\int_{l}^{\tilde{n}^{*}} \tilde{y}^{\mathbf{w}} d n+\int_{l}^{\tilde{n}^{*}} \tilde{w} n d n-\int_{l}^{\tilde{n}^{*}} \hat{c}^{\mathbf{w}} \tilde{w} n d n+\right. \\
\left.\quad-\int_{\tilde{n}^{*}}^{h} \tilde{y}^{\mathbf{e}} d n+\int_{\tilde{n}^{*}}^{h} s n d n-\int_{\tilde{n}^{*}}^{h} s \tilde{w} d n-\int_{\tilde{n}^{*}}^{h} \hat{c}^{\mathbf{e}} s(n-\tilde{w}) d n\right\}=\bar{R} .
\end{aligned}
$$

Since $\int_{l}^{\tilde{n}^{*}} \tilde{w} n d n=\tilde{w} \int_{\tilde{n}^{*}}^{h} \tilde{w} s d n$ from the labor market clearing condition (2), we get the resource constraint (9). 


\section{References}

Andreoni, J., Erard, B. and J. Feinstein. (1998). "Tax compliance", Journal of Economic Literature 36, 818-860.

Balestrino, A. and U. Galmarini (2002). "Presumptive taxation, markets and redistribution", ChilD Working Paper n. 08/2002, Turin.

Balestrino, A. and U. Galmarini (2003). "Imperfect tax compliance and the optimal provision of public goods." Bulletin of Economic Research 55, 37-52.

Bennet, J. (1987). "The second-best lump-sum taxation of observable characteristics." Public Finance 42, $227-235$.

Boadway, R., Marchand, M. and P. Pestieau. (1991). "Optimal linear income taxation in models with occupational choice." Journal of Public Economics 46, 133-162.

Boadway, R., Marchand, M. and P. Pestieau. (1994). "Towards a theory of the direct-indirect tax mix." Journal of Public Economics 55, 71-88.

Cnossen, S. and L. Bovenberg (2001). "Fundamental tax reform in the Netherlands." International Tax and Public Finance 8, 471-484.

Cowell, F.A. (1990a). Cheating the Government. The MIT Press.

Cowell, F.A. (1990b). "Tax sheltering and the cost of evasion". Oxford Economic Papers 42, 231-243.

Harrison, S. (1997). "Presumptive taxes in Central and Eastern Europe." International Bureau of Fiscal Documentation, Bulletin 51 (8/9), 393-397.

Kaplow, L. (1996). "How tax complexity and enforcement affect the equity and efficiency of the income tax." National Tax Journal 49, 135-150.

Sadka, E. and V. Tanzi. (1993). "A tax on gross assets of enterprises as a form of presumptive taxation." International Bureau of Fiscal Documentation, Bulletin 47 (2), 66-73.

Schneider, F. and D.H. Enste. (2002). The shadow economy. Cambridge University Press.

Slemrod, J. (1994). "Fixing the leak in Okun's bucket. Optimal tax progressivity when avoidance can be controlled." Journal of Public Economics 55, 41-51.

Slemrod, J. (2001). "A general model of the behavioral response to taxation." International Tax and Public Finance 8, 119-128..

Slemrod, J. and S. Yitzhaki (1994). "Analyzing the standard deduction as a presumptive tax." International Tax and Public Finance 1, 25-34.

Slemrod, J. and S. Yitzhaki (2002). "Tax avoidance, evasion, and administration." In: A.J. Auerbach and M. Feldstein. Handbook of Public Economics, vol. 3. Elsevier Science B.V., Amsterdam. 
Stern, N. (1982). "Optimum taxation with errors in administration." Journal of Public Economics 17, 181-211.

Tanzi, V. and M. Casanegra. (1989). "The use of presumptive income in modern tax systems." In: A. Chiancone and K. Messere. Changes in revenue structures. Wayne State University Press.

Taube, G. and H. Tadesse (1996). "Presumptive taxation in Sub-Saharan Africa: Experiences and prospects." IMF Working Paper WP/96/5. 


\section{CESifo Working Paper Series}

(for full list see www.cesifo.de)

1317 Attila Ambrus and Rossella Argenziano, Network Markets and Consumers Coordination, October 2004

1318 Margarita Katsimi and Thomas Moutos, Monopoly, Inequality and Redistribution Via the Public Provision of Private Goods, October 2004

1319 Jens Josephson and Karl Wärneryd, Long-Run Selection and the Work Ethic, October 2004

1320 Jan K. Brueckner and Oleg Smirnov, Workings of the Melting Pot: Social Networks and the Evolution of Population Attributes, October 2004

1321 Thomas Fuchs and Ludger Wößmann, Computers and Student Learning: Bivariate and Multivariate Evidence on the Availability and Use of Computers at Home and at School, November 2004

1322 Alberto Bisin, Piero Gottardi and Adriano A. Rampini, Managerial Hedging and Portfolio Monitoring, November 2004

1323 Cecilia García-Peñalosa and Jean-François Wen, Redistribution and Occupational Choice in a Schumpeterian Growth Model, November 2004

1324 William Martin and Robert Rowthorn, Will Stability Last?, November 2004

1325 Jianpei Li and Elmar Wolfstetter, Partnership Dissolution, Complementarity, and Investment Incentives, November 2004

1326 Hans Fehr, Sabine Jokisch and Laurence J. Kotlikoff, Fertility, Mortality, and the Developed World's Demographic Transition, November 2004

1327 Adam Elbourne and Jakob de Haan, Asymmetric Monetary Transmission in EMU: The Robustness of VAR Conclusions and Cecchetti's Legal Family Theory, November 2004

1328 Karel-Jan Alsem, Steven Brakman, Lex Hoogduin and Gerard Kuper, The Impact of Newspapers on Consumer Confidence: Does Spin Bias Exist?, November 2004

1329 Chiona Balfoussia and Mike Wickens, Macroeconomic Sources of Risk in the Term Structure, November 2004

1330 Ludger Wößmann, The Effect Heterogeneity of Central Exams: Evidence from TIMSS, TIMSS-Repeat and PISA, November 2004

1331 M. Hashem Pesaran, Estimation and Inference in Large Heterogeneous Panels with a Multifactor Error Structure, November 2004 
1332 Maarten C. W. Janssen, José Luis Moraga-González and Matthijs R. Wildenbeest, A Note on Costly Sequential Search and Oligopoly Pricing, November 2004

1333 Martin Peitz and Patrick Waelbroeck, An Economist's Guide to Digital Music, November 2004

1335 Lutz Hendricks, Why Does Educational Attainment Differ Across U.S. States?, November 2004

1336 Jay Pil Choi, Antitrust Analysis of Tying Arrangements, November 2004

1337 Rafael Lalive, Jan C. van Ours and Josef Zweimueller, How Changes in Financial Incentives Affect the Duration of Unemployment, November 2004

1338 Robert Woods, Fiscal Stabilisation and EMU, November 2004

1339 Rainald Borck and Matthias Wrede, Political Economy of Commuting Subsidies, November 2004

1340 Marcel Gérard, Combining Dutch Presumptive Capital Income Tax and US Qualified Intermediaries to Set Forth a New System of International Savings Taxation, November 2004

1341 Bruno S. Frey, Simon Luechinger and Alois Stutzer, Calculating Tragedy: Assessing the Costs of Terrorism, November 2004

1342 Johannes Becker and Clemens Fuest, A Backward Looking Measure of the Effective Marginal Tax Burden on Investment, November 2004

1343 Heikki Kauppi, Erkki Koskela and Rune Stenbacka, Equilibrium Unemployment and Capital Intensity Under Product and Labor Market Imperfections, November 2004

1344 Helge Berger and Till Müller, How Should Large and Small Countries Be Represented in a Currency Union?, November 2004

1345 Bruno Jullien, Two-Sided Markets and Electronic Intermediaries, November 2004

1346 Wolfgang Eggert and Martin Kolmar, Contests with Size Effects, December 2004

1347 Stefan Napel and Mika Widgrén, The Inter-Institutional Distribution of Power in EU Codecision, December 2004

1348 Yin-Wong Cheung and Ulf G. Erlandsson, Exchange Rates and Markov Switching Dynamics, December 2004

1349 Hartmut Egger and Peter Egger, Outsourcing and Trade in a Spatial World, December 2004

1350 Paul Belleflamme and Pierre M. Picard, Piracy and Competition, December 2004 
1351 Jon Strand, Public-Good Valuation and Intrafamily Allocation, December 2004

1352 Michael Berlemann, Marcus Dittrich and Gunther Markwardt, The Value of NonBinding Announcements in Public Goods Experiments: Some Theory and Experimental Evidence, December 2004

1353 Camille Cornand and Frank Heinemann, Optimal Degree of Public Information Dissemination, December 2004

1354 Matteo Governatori and Sylvester Eijffinger, Fiscal and Monetary Interaction: The Role of Asymmetries of the Stability and Growth Pact in EMU, December 2004

1355 Fred Ramb and Alfons J. Weichenrieder, Taxes and the Financial Structure of German Inward FDI, December 2004

1356 José Luis Moraga-González and Jean-Marie Viaene, Dumping in Developing and Transition Economies, December 2004

1357 Peter Friedrich, Anita Kaltschütz and Chang Woon Nam, Significance and Determination of Fees for Municipal Finance, December 2004

1358 M. Hashem Pesaran and Paolo Zaffaroni, Model Averaging and Value-at-Risk Based Evaluation of Large Multi Asset Volatility Models for Risk Management, December 2004

1359 Fwu-Ranq Chang, Optimal Growth and Impatience: A Phase Diagram Analysis, December 2004

1360 Elise S. Brezis and François Crouzet, The Role of Higher Education Institutions: Recruitment of Elites and Economic Growth, December 2004

1361 B. Gabriela Mundaca and Jon Strand, A Risk Allocation Approach to Optimal Exchange Rate Policy, December 2004

1362 Christa Hainz, Quality of Institutions, Credit Markets and Bankruptcy, December 2004

1363 Jerome L. Stein, Optimal Debt and Equilibrium Exchange Rates in a Stochastic Environment: an Overview, December 2004

1364 Frank Heinemann, Rosemarie Nagel and Peter Ockenfels, Measuring Strategic Uncertainty in Coordination Games, December 2004

1365 José Luis Moraga-González and Jean-Marie Viaene, Anti-Dumping, Intra-Industry Trade and Quality Reversals, December 2004

1366 Harry Grubert, Tax Credits, Source Rules, Trade and Electronic Commerce: Behavioral Margins and the Design of International Tax Systems, December 2004

1367 Hans-Werner Sinn, EU Enlargement, Migration and the New Constitution, December 2004 
1368 Josef Falkinger, Noncooperative Support of Public Norm Enforcement in Large Societies, December 2004

1369 Panu Poutvaara, Public Education in an Integrated Europe: Studying to Migrate and Teaching to Stay?, December 2004

1370 András Simonovits, Designing Benefit Rules for Flexible Retirement with or without Redistribution, December 2004

1371 Antonis Adam, Macroeconomic Effects of Social Security Privatization in a Small Unionized Economy, December 2004

1372 Andrew Hughes Hallett, Post-Thatcher Fiscal Strategies in the U.K.: An Interpretation, December 2004

1373 Hendrik Hakenes and Martin Peitz, Umbrella Branding and the Provision of Quality, December 2004

1374 Sascha O. Becker, Karolina Ekholm, Robert Jäckle and Marc-Andreas Mündler, Location Choice and Employment Decisions: A Comparison of German and Swedish Multinationals, January 2005

1375 Christian Gollier, The Consumption-Based Determinants of the Term Structure of Discount Rates, January 2005

1376 Giovanni Di Bartolomeo, Jacob Engwerda, Joseph Plasmans, Bas van Aarle and Tomasz Michalak, Macroeconomic Stabilization Policies in the EMU: Spillovers, Asymmetries, and Institutions, January 2005

1377 Luis H. R. Alvarez and Erkki Koskela, Progressive Taxation and Irreversible Investment under Uncertainty, January 2005

1378 Theodore C. Bergstrom and John L. Hartman, Demographics and the Political Sustainability of Pay-as-you-go Social Security, January 2005

1379 Bruno S. Frey and Margit Osterloh, Yes, Managers Should Be Paid Like Bureaucrats, January 2005

1380 Oliver Hülsewig, Eric Mayer and Timo Wollmershäuser, Bank Loan Supply and Monetary Policy Transmission in Germany: An Assessment Based on Matching Impulse Responses, January 2005

1381 Alessandro Balestrino and Umberto Galmarini, On the Redistributive Properties of Presumptive Taxation, January 2005 